\title{
Surgical Management of Infantile Hypertrophic Pyloric Stenosis by Double-Y Pyloromyotomy: A Better Approach
}

\author{
Ali MA ${ }^{1}$, Hasina $\mathrm{K}^{2}$, Naim A ${ }^{3}$, Israil MA ${ }^{4}$, Alam $\mathrm{MM}^{5}$, Talukder $\mathrm{AR}^{6}$, Yusuf $\mathrm{MA}^{7}$, \\ Rahman $\mathrm{MK}^{8}$, Rahman NMW ${ }^{9}$, Hossain $\mathrm{MA}^{10}$
}

\begin{abstract}
Background: Various treatment modalities have been applied for the management of infantile hypertrophic pyloric stenosis. However surgery remains the mainstay of treatment for IHPS of which Ramstedt's pyloromyotomy remains the surgical technique of choice. Objective: To see the outcome of surgical management of infantile hypertrophic pyloric stenosis by double-Y pyloromyotomy. Methods: A prospective interventional study of 40 patients with IHPS was carried out over a period of 2 years from July 2008 to July 2010. The patients were divided into 2 equal groups of 20 patients in each. All patients selected for study were optimized preoperatively regarding to hydration, acid-base status and electrolytes imbalance. All surgeries were performed after obtaining informed consent. Standard preoperative preparation and postoperative feeding regimes were used. The patients were operated on an alternate basis, i.e., one patient by Double-Y Pyloromyotomy (DY) and the next by a Ramstedt's Pyloromyotomy (RP). Data on patient demographics, operative time, anaesthesia complications and postoperative complications including vomiting and weight gain were collected. Patients were followed up for a period of 3 months postoperatively. Statistical assessments were done by using t test. Results: From July 2008 through July 2010, forty patients were finally analyzed for this study. Any statistical differences were observed in patient population regarding age, sex, weight at presentation, symptoms and clinical condition including electrolytes imbalance and acid-base status were recorded. Significant differences were found in postoperative vomiting and weight gain. Data of post operative vomiting and weight gain in both groups were collected. Vomiting in double-Y(DY) pyloromyotomy group vs Ramstedt's pyloromyotomy (RP) group was significant ( $\mathrm{p}=0.0001)$. Weight gain after 1 st 10 days DY vs RP is $298 \pm 57.94 \mathrm{gm}$ vs $193 \pm 19.8 \mathrm{gm}$ (p=0.0014), after 1 month $676.67 \pm 149.84 \mathrm{gm}$ vs $466.67 \pm 127.71 \mathrm{gm}(\mathrm{p}=0.0001)$, after 2 months $741.33 \pm 278.74 \mathrm{gm}$ vs $490 \pm 80.62 \mathrm{gm}$ ( $\mathrm{p}=0.002)$ and after 3 months $582 \pm 36.01 \mathrm{gm}$ vs $453.33 \pm 51.64 \mathrm{gm}(\mathrm{p}=0.0001)$. No long-term complications were reported and no re-do pyloromyotomy was needed. Conclusion: The double-Y pyloromyotomy seems to be a better technique for the surgical management of IHPS. It may offer a better functional outcome in term of postoperative vomiting and weight gain.
\end{abstract}

Key wards: Pyloric stenosis, pyloromyotomy, double-Y pyloromyotomy, Alayet's pyloromyotomy

\section{Introduction}

Infantile hypertrophic Pyloric Stenosis (IHPS) is a common cause of gastric outlet obstruction in infants. It was first described by Blair ${ }^{1}$ in an autopsy report. It's prevalence ranges from 1.5 to 4 per 1000 live births ${ }^{2}$. Different treatment modalities and procedures have been tried for the management of this common condition. Simple observation to surgery have all been tried and tested. Pharmacological interventions have been used in a few centres. However, for practical purposes, surgery remains the mainstay for management of IHPS. Many innovations and approaches have been carried out for surgical management of IHPS. First successful surgery was performed by Dufour and Fredet ${ }^{3}$ which was longitudinally splitting of hypertrophic pyloric muscle and transversely closing. But Ramstedt ${ }^{4}$ stated that no need of muscle closure and from that period it was known as Ramstedt's pyloromyotomy. Ramstedt's pyloromyotomy was remained the surgical treatment of choice for about a hundred years. Here a new technique focusing on pylorus, which may

1. Dr. Md. Ansar Ali, Department of Paediatric Surgery, Dhaka Medical College \& Hospital, Dhaka

2. Dr. Kaniz Hasina, Assistant Professor, Department of Paediatric Surgery, Dhaka Medical College \& Hospital Dhaka

3. Dr. Abu Naim, Resident Physician, Department of Medicine, Shaheed Suhrawardy Medical College, Dhaka

4. Dr. Md. Anwar Israil, EMO, Mitford Hospital, Dhaka

5. Prof. Dr. Md. Mahbub-Ul-Alam, Professor \& Head, Department of Pediatric Surgery, Dhaka Medical College \& Hospital, Dhaka

6. Dr. Abdur Rabban Talukder, Senior Consultant, Department of Surgery, General Hospital, Sirajgonj

7. Dr. Md. Abdullah Yusuf, Lecturer, Department of Microbiology, Shaheed Suhrawardy Medical College, Dhaka

8. Dr. Md. Khalilur Rahman, Assistant Professor, Department of Radiology \& Imaging, Dhaka Medical College, Dhaka

9. Dr. Nawshad Muhammad Wahidur Rahman, Assistant Professor, Department of Microbiology, Eastern Medical College \& Hospital, Comilla

10. Dr. Md. Afzal Hossain, Assistant Professor, Department of Microbiology, Nightingale Medical College, Dhaka

\section{Correspondence:}

Dr. Md. Ansar Ali, Department of Pediatric Surgery, Dhaka Medical College \& Hospital Dhaka, Bangladesh. Mobile : 01711468528

E-mail : dr.ansar09@gmail.com 
offer better results for this common condition. Alalayet et $\mathrm{al}^{5}$ introduced this new technique known as Alayet's Double-Y Pyloromyotomy. Various treatment modalities have been applied for the management of infantile hypertrophic pyloric stenosis. However surgery remains the mainstay of treatment for IHPS of which Ramstedt's pyloromyotomy remains the surgical technique of choice. An alternative technique is the double-Y pyloromyotomy which offer better results for management of this common condition.

The aim of the present study was to see the outcome of surgical management of infantile hypertrophic pyloric stenosis by double-Y pyloromyotomy.

\section{Methodology}

A prospective comparative interventional study was planned to make a comparison between Ramstedt's pyloromyotomy and double-Y pyloromyotomy. The approval of the ethical committee was obtained after a detailed discussion of the procedure and study design. A total of 40 patients with infantile hypertrophic pyloric stenosis were included for the period from July 2008 to July 2010. Patients with other congenital problems or comorbid medical conditions were excluded from the study and additionally, patients who were operated by other surgeons in the department were included. At the end, only 40 patients were included in the study. All patients selected for the study were optimized preoperatively with regard to hydration, acid-base status and electrolyte imbalance. Patients were divided into 2 equal groups having 20 patients in each. Standard preoperative preparation and postoperative feeding regimes (1st feed 4 hours after surgery with dextrose water moving to half-strength milk and proceeding to full feeds within the first 24 postoperative hours) were used. All surgeries were performed after obtaining informed consent. Patients were operated on an alternate basis like one patient by double-Y pyloromyotomy and the next one by Ramstedt's pyloromyotomy. All patients were operated using the standard right upper quadrant (RUQ) transverse incision. Information on patient's demographics, operative times, anaesthesia complications, complications, postoperative vomiting and weight gain were collected. Parents were provided with a vomiting record sheet and were recorded the number of vomits per day and for how long vomiting took place postoperatively like both the frequency and duration of vomiting were recorded. These records were analyzed to assess end point vomiting. Patients were followed up for a period of 3 months postoperatively. Data was plotted on Microsoft Excel and analyzed with SPSS version 17 by using the Student's t-test. Results were expressed as mean \pm SD.

\section{Technique}

Ramstedt's pyloromyotomy had been done in the standard manner using the right upper quadrant transverse incision. In the double-Y pyloromyotomy (Alayet's pyloromyotomy), the incision was similar like a right upper quadrant transverse incision was used. The hypertrophoid pylorus was delivered and holding with thumb and index. A straight incision was made along $70 \%$ of the length of the hypertrophied pylorus in the centre. The sides were made like a $\mathrm{V}$ and each $\mathrm{V}$ represented the remaining $15 \%$ of the incision length. The final appearance of the incision resembled double-Y. The straight line was dilated first by using the reverse sides of an artery forceps, then $\mathrm{V}$-incision were dilated for pouting of mucosa. After checking of any mucosal perforation, abdominal closure was closed in layers.

\section{Results}

A total of 40 patients were included in the study. 20 under went Ramstedt's pyloromyotomy (RP) and 20 had a double-Y pyloromyotomy (DY). The operative time was the same and no intraoperative complications occurred. No wound infections were encountered and no redo-pyloromyotomies were needed. No significant statistical differences were found in the patient population with regard to age (DY Group $39.33 \pm 8.06$ days vs. RP Group $39.33 \pm 5.09$ days; $p=1.000$ ), sex (DY 9F/11M vs. RP 9F/11 M), weight at presentation (DY $3.09 \pm 0.59 \mathrm{~kg}$ vs. RP $3.08 \pm 0.56 \mathrm{~kg} ; \mathrm{p}=0.975$ ), symptoms and clinical condition including electrolyte imbalance and acid-base status (all patients were optimally corrected before proceeding to surgery). Both groups were also equal in terms of general anaesthesia. However a significant difference between DY vs. RP groups was noted with regard to vomiting and weight gain. Patients were followed up for a period of 3 months postoperatively. Vomiting in double-Y(DY) pyloromyotomy group (1.21 \pm 0.45 days) vs Ramstedt's pyloromyotomy (RP) group $(3.03 \pm 0.37$ days $)(p=0.0001)$. Weight gain after 1 st 10 days DY vs RP is $(298 \pm 57.94$ gm vs $193 \pm 19.8$ gm $(\mathrm{p}=0.0014)$, after 1 month $676.67 \pm 149.84 \mathrm{gm}$ vs $466.67 \pm 127.71 \mathrm{gm}$, $(\mathrm{p}=0.0001)$, after 2 months $(741.33 \pm 278.74$ gm vs $490 \pm 80.62$ gm, $\mathrm{p}=0.002)$ and after 3 months $(582 \pm 36.01 \mathrm{gm}$ vs $453.33 \pm 51.64$ gm, $\mathrm{p}=0.0001)$. No long-term complications were reported and no re-do pyloromyotomy was needed.

\section{Discussion}

Infantile hypertrophic pyloric stenosis (IHPS) was first described by Blair ${ }^{1}$ in an autopsy specimen. A few other reports were published over the next 100 years, but the first detailed account was given by Hirschsprung ${ }^{2}$. IHPS remained an untreatable and usually fatal condition until 1907. First successful surgery was performed by Dufour and Fredet ${ }^{3}$. They suggested splitting the muscle and then suturing transversely. However Ramstedt ${ }^{4}$ described the classical operation and stated that there was no need for muscle closure and the procedure has remained in general use up until the present day. IHPS is a common cause of gastric outlet obstruction in infants and the prevalence ranges from 1.5-4.0/1000 live births among whites though the incidence is lower in black Americans and Asians ${ }^{6}$. The male to female ratio is ranges between $2: 1$ and $5: 1^{7}$. The majority of cases present between the 3rd and 5th week of age, although some cases are diagnosed at birth ${ }^{6}$ and some have even been diagnosed in utero ${ }^{8}$. The exact aetiology is 
unknown and why this usually occurs in the first-born child is also a question that still awaits an answer. Persons with a positive familial history and certain ABO blood groups show a higher incidence. Among the acquired factors, the methods of feeding (breast versus bottle) and seasonal variability have been implicated ${ }^{9}$. Prenatal prescription of macrolides has been implicated in the pathophysiology of IHPS $^{10}$. Decreased numbers of interstitial cells of Cajal and heme oxygenase- 2 have been found in the smooth muscle of IHPS ${ }^{11}$. Increased vascularity has been shown to be an integral component of the pylorus in IHPS ${ }^{12}$. An increased amount of desmin in the hypertrophied pylorus may be the cause of in-coordination of contraction and relaxation ${ }^{13}$. Management has come a long way from simple observation to treatment with intravenous atropine sulphate although this is not favored by most centers ${ }^{14}$. Traumamyoplasty (crushing with Babcock forceps) has been carried out satisfactorily at few centres ${ }^{15}$. Endoscopic balloon dilatation and endoscopic pyloromyotomy using endoscopic electrosurgical needle or a sphincterotome ${ }^{16}$ have also been described. However surgery remains the mainstay of the treatment and is safely and routinely done at most centres. The classical Ramstedt's procedure is conventionally done through a right upper transverse incision. Tan and Bianchi ${ }^{17}$ modified it to be done through a supra-umbilical semicircular incision for better cosmesis. An umbilical sliding window technique introduced in Japan has reduced the incidence of postoperative wound infection further than the Bianchi procedure ${ }^{18}$. A right semicircular umbilical technique offered superior results, especially for large tumours compared to Bianchi's procedure ${ }^{19}$ with much less damage to the pylorus and superior results in terms of infection. A squeeze technique is useful especially for the delivery of large pyloric tumors through the supra-umbilical route $^{20}$. Transumbilical pyloromyotomy has been described as an alternative to laparoscopy ${ }^{21}$. Since a significant period of time pyloromyotomy have been carried out laparoscopically. Double-Y pyloromyotomy also can be done laparoscopically. In this study postoperative vomiting is significantly less in the double-Y group compared to the Ramstedt procedure group. The weight gain in the patients is comparable to that in a study done a few years $\mathrm{ago}^{22}$. Double-Y pyloromyotomy (DY) had proved to be equally safe and efficacious compared to the Ramstedt's procedure. However in a meta-analysis, it was found that the functional outcome of the Double-Y technique was a better to others procedure. As the end force on the mucosa is divided into 2 directions it may be that the chances of perforation are lower. The method is suitable for both conventional and laparoscopic surgery.

\section{Conclusion}

Double-Y pyloromyotomy seems to offer a better and wider opening of the pylorus by creating a wider opening of the pyloric canal at the ends with a wide angle compared to other method like Ramstedt's pyloromyotomy, where the ends are sharply narrowed. A double-Y pyloromyotomy
(Alayet's pyloromyotomy) may offer a better functional outcome as seen by the lower frequency of vomiting in this study. The increased weight gain in the double-Y group may also indirectly indicate a wider and more effective opening of both ends of the pyloric canal. However more studies need to be done on this technique to prove its efficacy and establish it as a standard technique for the future.

\section{Acknowledgements}

I would like to sincerely thank Prof. Dr. Yasen Fayez Alalayet, who first stated the method for surgical management of IHPS, and other co-authors who help me for this study.

\section{References}

1. Blair P. On the dissection of a child much emaciated. Phil Trans ;1717;30:631-632 2. Hirschprung H, Fallen VA. Pylorus Stenosis. Jb Kinderheilk; 1888;27: 61

3. Dufour H, Fredet P. La stenose hypertrophique du pylore chez le nourissonet son traitment chirurgical. Rev Chir; 1908;37:208-253

4. Ramstedt C. Zur Operation der angeborenen pylorus stenosis. Med Klinik; 1912;8:1702

5. Alalayet YF, Miserez M, Mansoor K, Khan AM. Double-Y pyloromyotomy: a new technique for the surgical management of infantile hypertrophic pyloric stenosis. Eur J Pediatr Surg. 2009;19(1):17-20

6. Mitchell LE et al. The genetics of IHPS. Am J Dis Child ; 1993;147:1203

7. Zenn MR et al. Hypertrophic pyloric stenosis. J Pediatr Surg; 1993;28:1577

8. Katz S et al. Prenatal gastric dilatation \& IHPS. J Pediatr Surg 1978;13:17

9. Ramussen L, Green A, Hansen LP. The epidemiology of infantile hypertrophic pyloric stenosis in a Danish population. Int J Epidemol, 1989;18:413

10. Cooper WO, Ray WA,Griffin MR. Prenatal prescription of macrolide antibiotics and infantile hypertrophic pyloric stenosis. Obstet Gynecol,2003;101:816-817

11. Piotrowska AP, Solari V, Puri P. Distribution of heme oxygenase-2 innerves and interstitial cells of Cajal in the normal pylorus and in infantile hypertrophic pyloric stenosis. Arch Pathol Lab Med, 2003;127:1182-1186

12. Hernanz-Schulman M. Hypertrophic pyloric stenosis in infants: US evaluation of vascularity of the pyloric canal. Radiology; 2003;229:389-393 13. Guarino N, Shima H, Prem P. Structural immaturity of the pylorus muscle in infantile hypertrophic pyloric stenosis. Pediatr Surg Int; 2000; 16:282-284

14. Meissner PE et al. Conservative treatment of infantile hypertrophic pyloric stenosis with intravenous atropine sulphate does not replace pyloromyotomy. Pediatr Surg Int, 2006;22:1021-1024

15. Ordorica-Flores R-et-al. Infantile hypertrophic pyloric stenosis: a comparative study of traumamyoplasty and Fredet-Ramstedt pyloromyotomy.J Pediatr Surg, 2001; 36:1000-1003

16. Ibarguen-Secchia E et al. Endoscopic pyloromyotomy for congenital pyloric stenosis. Gastro Endo 2005;61:598-600

17. Tan KC, Bianchi A. Circumumbilical incision for pyloromyotomy. Br J Surg 1986;73:399

18. Yokomori $\mathrm{K}$ et al. Pyloromyotomy through a sliding umbilical window. J Pediatr Surg, 2006; 41:2066-2068

19. Alberti D, Cheli M, Locatelli G. A new technical variant for extramucosal pyloromyotomy: the Tan-Bianchi operation moves to the right. J Pediatr Surg 2004; 39:53-56

20. Mahomed AA, Panchalingum L, Nikolopoulos Y. The squeeze technique to assist transumbilical delivery of pyloric tumor. J Pediatr Surg, 2006;41:1492-1494

21. Shankar KR et al.; Umbilical pyloromyotomy- an altrnative to laparoscopy? Eur J Pediatr Surg, 2001;11:8-11

22. Van der Bilt JDWet al. Early feeding after laparoscopic pyloromyotomy. Surg Endos 2004; 18: 746-748 